\title{
Familial and nonfamilial benign recurrent cholestasis distinguished by plasma disappearance of indocyanine green but not cholylglycine ${ }^{1}$
}

\author{
G. P. VAN BERGE-HENEGOUWEN, ${ }^{2}$ D. R. FERGUSON, ${ }^{3}$ A. F. HOFMANN, ${ }^{4}$ \\ AND A. G. F. DE PAGTER ${ }^{5}$ \\ From the Gastroenterology Unit, Mayo Clinic, Rochester, Minnesota, USA, and Department of Internal \\ Medicine, St. Radboud Hospital, Nijmegen, The Netherlands
}

\begin{abstract}
SUMMARY To determine whether a defect in uptake of organic anions is present in patients with benign recurrent cholestasis, the plasma disappearance of simultaneously injected indocyanine green and cholylglycine-1-14 $\mathrm{C}$ was measured in eight patients with asymptomatic benign recurrent cholestasis, four with the familial type, as well as 22 healthy control subjects. Evans blue was also simultaneously injected to permit correction for variation in blood volume and speed of mixing. Uptake of indocyanine green was decreased in all three patients with nonfamilial benign recurrent cholestasis, but normal or increased in the four patients with the familial form of the disorder. By contrast, cholylglycine-1-14 $\mathrm{C}$ uptake was abnormal in one patient with each type of the disorder. Thus, patients with nonfamilial benign recurrent cholestasis have a defect in indocyanine green uptake, and patients with benign recurrent cholestasis are heterogeneous with respect to organic anion uptake.
\end{abstract}

Benign recurrent cholestasis has been described in a nonfamilial form (Summerskill and Walshe, 1959; Summerskill, 1965) and also in a familial form (Tygstrup and Jensen, 1969). We also recently observed a family with four affected members with benign recurrent cholestasis, where, in addition, many members manifested cholestasis during pregnancy or when taking oral contraceptives (de Pagter et al., 1976). We studied one of these patients

\footnotetext{
${ }^{1}$ This work was supported in part by the National Institutes of Health, Grant AM 16770 and the Netherlands Organization for the Advancement of Pure Research. It was presented at the 11th Annual Meeting of the European Society for Clinical Investigation, 21-23 April, 1977, Rotterdam, The Netherlands.

2Address for reprint requests: Dr G. P. v. BergeHenegouwen, St. Radboud Hospital, Nijmegen, The Netherlands.

${ }^{3}$ Present address: Division of Gastroenterology, Cleveland Clinic, Cleveland, Ohio 44106.

'Present address: Department of Medicine, University of California at San Diego, San Diego, California.

'Present address: General practice, Ysselmuiden, The Netherlands.
}

Received for publication 21 November 1977 during the prodromal stage of an episode of cholestasis and observed increased serum levels of bile acids, alkaline phosphatase, and 5'-nucleotidase, although the serum bilirubin levels remained normal. Two explanations were considered to explain these findings. On the one hand, patients with familial benign recurrent cholestasis might have a selective defect in bile acid uptake (van BergeHenegouwen et al., 1974); on the other hand, the fact that serum bilirubin levels did not increase, although bile acid levels were raised might merely reflect the known insensitivity of bilirubin measurements in patients with liver disease (Fausa and Gjone, 1976; Osuga et al., 1977; Simmonds et al., 1973).

To distinguish between these possibilities and to gain further insight into the pathogenesis of the disorder, we have described the plasma disappearance of two hepatophilic anions, indocyanine green and cholylglycine, in patients with familial and nonfamilial benign recurrent cholestasis. As these substances are taken up exclusively by the liver (Paumgartner, 1975; Ng and Hofmann, 1977), we have equated plasma disappearance with hepatic uptake. Plasma disappearance of these hepatophiles was also described in 22 healthy subjects to provide data for comparison. 
Methods

PATIENTS

Eight asymptomatic patients were studied after informed consent was obtained; all fulfilled the criteria proposed by Tygstrup in 1969. Criteria for an asymptomatic phase were: (1) no clinical symptoms or abnormalities; (2) normal liver tests-for example, normal levels of alkaline phosphatase, 5'-nucleotidase, $\gamma$-glutamyl transpeptidase, SGOT, SGPT, and bilirubin (all patients had normal bromosulphalein retention $(5 \mathrm{mg} / \mathrm{kg})$ during a previously asymptomatic phase); (3) normal liver histology without any evidence of cholestasis during an earlier asymptomatic phase. In this way, eight asymptomatic patients were selected for the study.

Four Dutch patients with the familial form of the disorder $\left(\mathrm{F}_{1}-\mathrm{F}_{4}\right)$ had already been described in detail (de Pagter et al., 1976). Three American patients had nonfamilial benign recurrent cholestasis $\left(\mathrm{NF}_{5}-\mathrm{NF}_{7}\right)$ and had been seen previously at the Mayo Clinic. One patient $\left(\mathrm{U}_{8}\right)$ may have had the familial type of the disorder, as he had a brother with a history of two episodes of jaundice; however, the brother refused to be studied.

\section{DESIGN}

Eight patients with benign recurrent cholestasis and 22 healthy volunteers were studied. The healthy volunteers had normal conventional liver tests. A mixture of indocyanine green, cholylglycine-1-14 C, and Evans blue (as blood volume marker) was injected intravenously as a bolus into the patient after an overnight fast (Ferguson et al., 1976). An indwelling catheter was placed in the other antecubital vein and blood samples were taken at $2,4,6,8$, $10,12,15$, and 20 minutes. We have shown previously that the plasma disappearance of indocyanine green is not influenced by the simultaneous injection of cholylglycine and vice versa; that the plasma disappearance of cholylglycine is independent of mass up to $5 \mu \mathrm{mol} / \mathrm{kg}$; and that Evans blue has no influence on the plasma disappearance of indocyanine green or cholylglycine (Calcraft et al., 1975; Ferguson et al., 1976).

\section{TECHNIQUES}

Indocyanine green was determined spectrophotometrically at $810 \mathrm{nM}$. The absorbance was determined before and after decolourisation with hydrochloric acid. Evans blue was determined spectrophotometrically at $620 \mathrm{nM}$. Cholylglycine-1-14C was determined by liquid scintillation spectroscopy. Results were expressed as percentage remaining, by determining the ratio of hepatophile to Evans blue $(\times 100)$ as well as by $\%$ dose/l, using a figure of
$50 \mathrm{ml} / \mathrm{kg}$ for blood volume. We have suggested the use of Evans blue to allow correction for delayed mixing as well as biological differences in blood volume (Ferguson et al., 1976).

\section{Results}

\section{INDOCYANINE GREEN}

When retention of indocyanine green was calculated on the basis of Evans blue measurements, all three patients with nonfamilial benign recurrent cholestasis had prolonged retention compared either with the four patients with the familial disorder or the healthy controls (Fig. 1). The same difference was also observed if retention was calculated as \% dose/1 (Fig. 2). Patient $\mathrm{U}_{8}$ had greatly impaired clearance of indocyanine green, and he thus behaved as a nonfamilial patient.

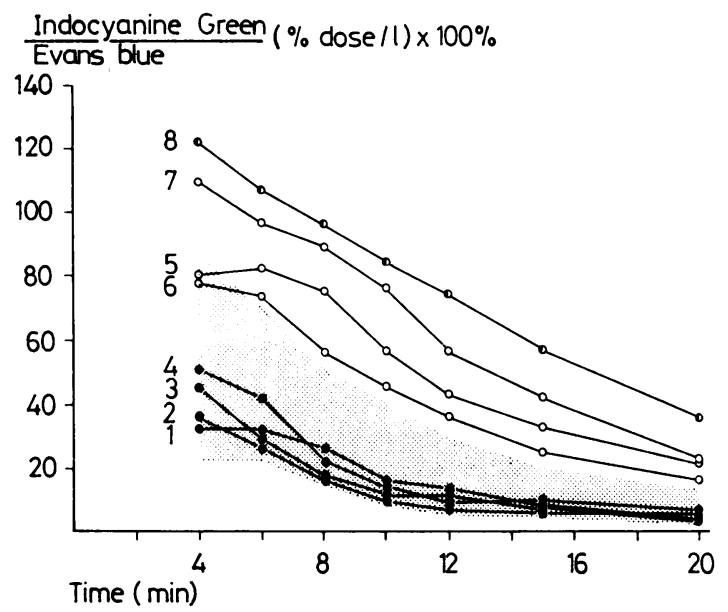

Fig. 1 Hepatic indocyanine green clearances relative to Evans blue concentration as the plasma volume marker in patients with familial (1-4) and nonfamilial (5-8) benign recurrent cholestasis.

$\because::$ Normal controls $(n=22 ;$ mean $\pm 2 S D) \bigcirc B R C$ (one family). $\bigcirc B R C$ (non-familial type). (D Nonfamilial?

\section{CHOLYLGLYCINE}

In contrast with that of indocyanine green, plasma disappearance of cholylglycine was normal in two patients with the nonfamilial disorder and equivocal in the third (patient 5) (Figs 3 and 4). Patient 8, whose type of benign recurrent cholestasis could not be defined, had delayed cholylglycine clearance. Patient 1, with the familial type, had a highly abnormal cholylglycine clearance. As this patient 

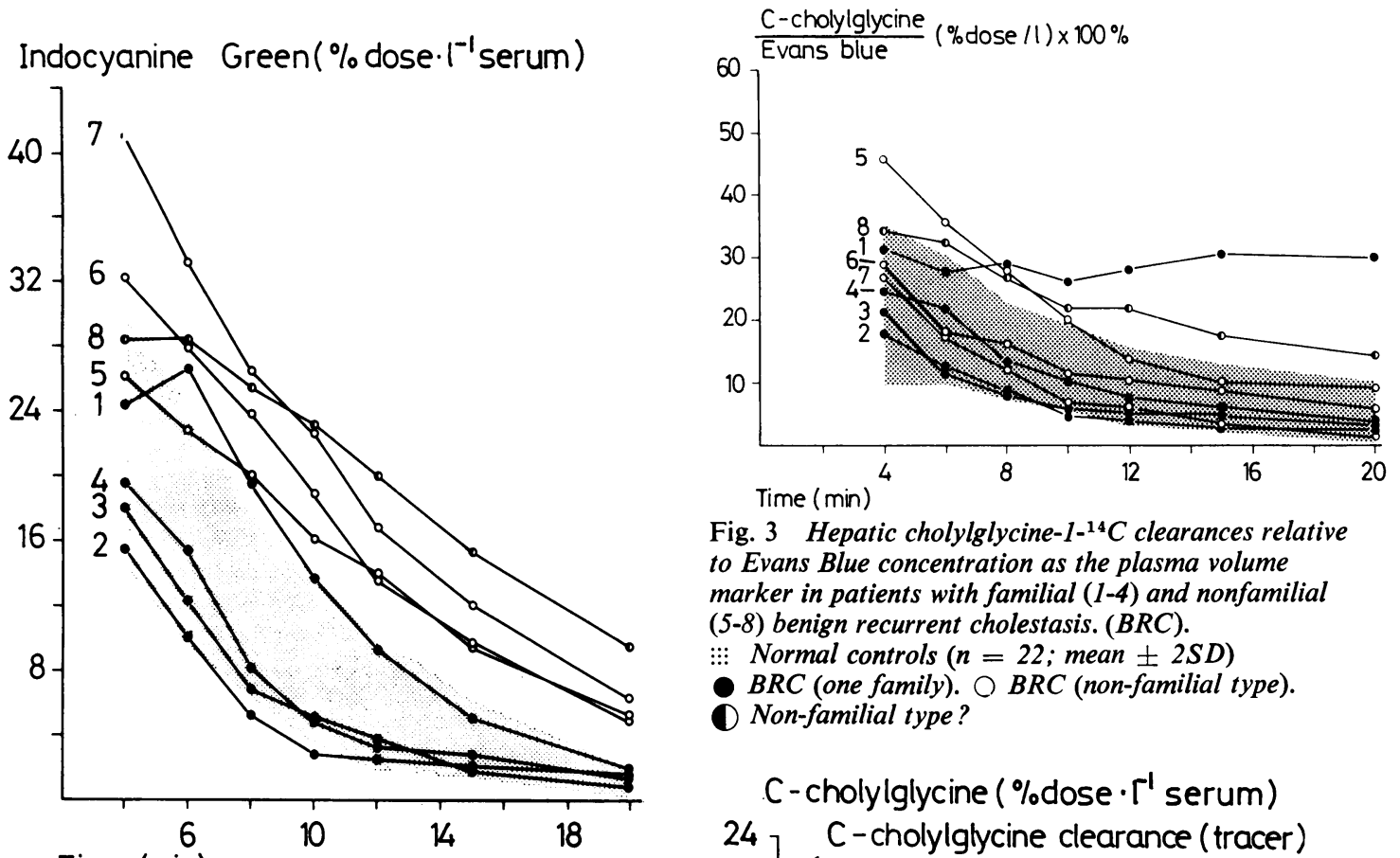

Fig. 3 Hepatic cholylglycine- $1-{ }^{14} \mathrm{C}$ clearances relative to Evans Blue concentration as the plasma volume marker in patients with familial (1-4) and nonfamilial (5-8) benign recurrent cholestasis. (BRC).

$:::$ Normal controls $(n=22 ;$ mean $\pm 2 S D)$

- $B R C$ (one family). $\bigcirc B R C$ (non-familial type).

D Non-familial type?

Time (min)

Fig. 2 Hepatic indocyanine green clearance in percentage dose/l in patients with familial (1-4) and nonfamilial (5-8) benign recurrent cholestasis.

$:::$ Normal controls $(n=22 ;$ mean $\pm 2 S D)$

$\bigcirc$ Benign recurrent cholestasis (non-familial type, $n=3$ )

- Benign recurrent cholestasis (familial type, $n=4$ )

Non-familial type?

had several exacerbations each year, it is possible that she was not truly asymptomatic, although conventional liver function tests were normal at the time of the clearancestudies. Thus, according to our criteria, patient 1 was asymptomatic.

\section{CLEARANCES}

In Figure 5 the 10-minute value tor cholylglycine and indocyanine green for all patients and normal controls is shown. We have previously suggested that the 10-minute value may be a useful time interval since it is long enough for complete mixing of the hepatophile, but short enough accurately to measure the amount in serum (LaRusso et al., 1975).

\section{Discussion}

TYPES OF BENIGN RECURRENT CHOLESTASIS DISTINGUISHED

These results show that three asymptomatic patients with the nonfamilial disorder have abnormalities in uptake of indocyanine green, but not cholylglycine. One patient, whose type of the disorder was not

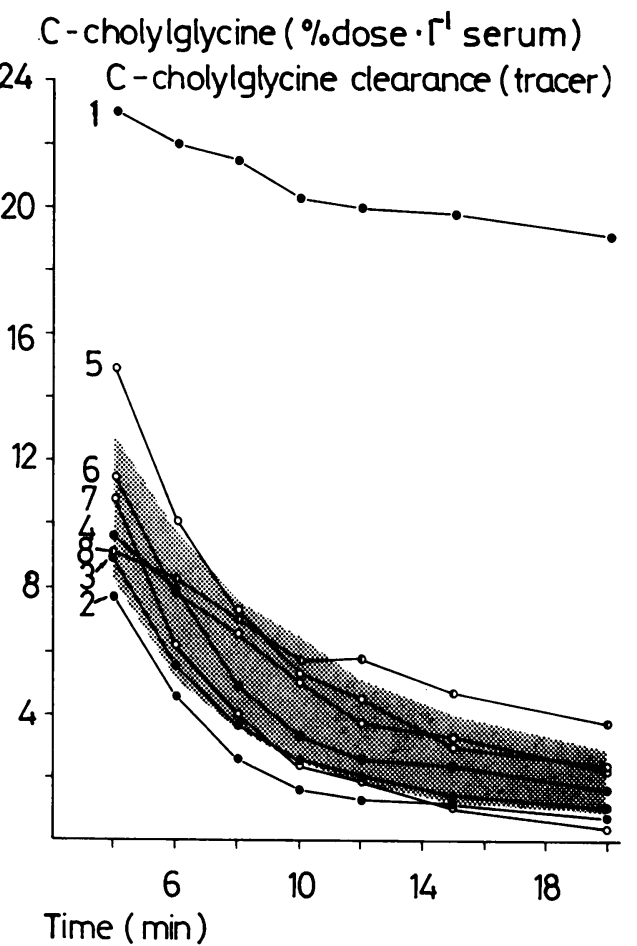

Fig. 4 Hepatic cholylglycine-1-14C clearance in percentage dose/l in patients with the familial (1-4) and the nonfamilial (5-8) forms of benign recurrent cholestasis. ::: Normal controls $(n=22$ : mean \pm $2 S D)$. $\bigcirc$ Benign recurrent cholestasis (non-familial type, $n=3$ ). Benign recurrent cholestasis (familial type, $n=4)$. (D Non-familial type?. 

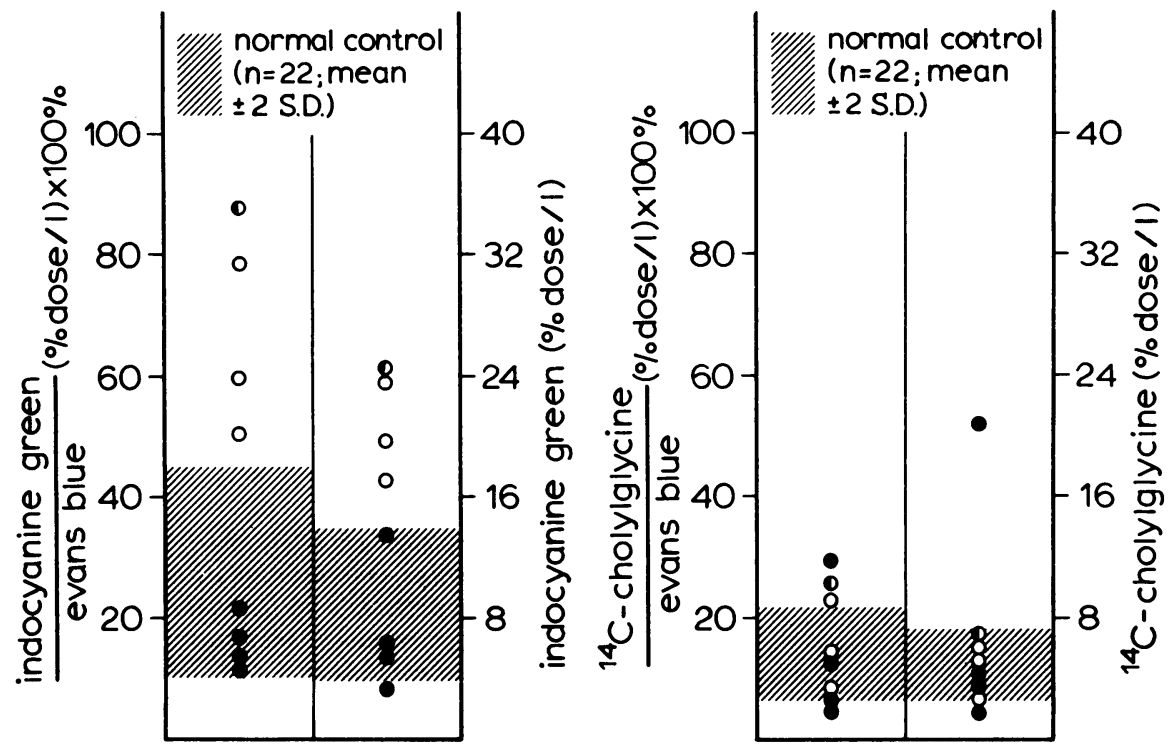

Fig. 5 Ten-minute values for indocyanine green (left) and cholylglycine (right) clearances in patients with familial $(\bigcirc)$ and nonfamilial $(O)$ benign recurrent cholestasis. (1) non familial? benign recurrent cholestasis.

defined, had delayed uptake of both anions. The four Dutch patients with the familial type had normal uptake of both anions, with the exception of patient 1 , who had an abnormal cholylglycine clearance.

Our results provide no insight into the biochemical abnormality responsible for benign recurrent cholestasis, but they do suggest an abnormality in the hepatocyte membrane persisting in the latent phase of the disease. Further, they suggest that hepatic blood flow is normal in the majority of patients with the disorder, as cholylglycine clearance, which is probably blood flow limited, was within normal limits. Okuda et al. (1976) have described a group of patients with an isolated defect in Indocyanine Green uptake. The relationship of this abnormality is unknown.

\section{INDOCYANINE GREEN VS CHOLYLGLYCINE} Indocyanine green uptake was more frequently abnormal than cholylglycine uptake in patients with the nonfamilial type of the disorder. We have reported previously in abstract form that Indocyanine green uptake is more sensitive than cholylglycine uptake in patients with a variety of liver diseases (Ferguson et al., 1976), and Barnes et al. (1976) have also observed that plasma disappearance of injected bile acid is frequently normal in patients with liver disease. The present study represents the first comparison of the simultaneous uptake of these two prototypic hepatophiles in patients with benign recurrent cholestasis. We have reported previously that cholylglycine uptake was an extremely sensitive test of liver function (or injury) (LaRusso et al., 1975), but the group of patients reported there was composed predominantly of patients with chronic active hepatitis, and some of these may have had impaired hepatic blood flow because of concomitant cirrhosis.

Fractional indocyanine green uptake decreases as the load is increased (Paumgartner, 1975), but it seems unlikely that the use of a higher dose would have detected an abnormality in the patients with the familial disorder, as, on the average, uptake was more rapid than that observed for the healthy control subjects. Decreased fractional uptake of a large load of indocyanine green has been shown by Martin et al. (1976) to distinguish types of Gilbert's syndrome.

\section{TECHNIQUES}

The techniques employed in these studies would appear to be a rational way for assessing immediate uptake of two of the major classes of compounds extracted by the liver. Indocyanine green uptake presumably involves the same uptake mechanism as bilirubin, as in the rat, at least, uptake is competitive (Scharschmidt et al., 1975). Cholylglycine uptake, by definition, involves the uptake pathway for bile acids. The use of a plasma volume marker, Evans blue, permits correction for slow mixing, which may 
take three to eight minutes in man, as well as correction for blood volume. The idea is similar to that used by Goresky (1964) for defining uptake by the liver, or the use of PEG for intestinal absorption studies in man (Borgström et al., 1957).

It should be noted that for indocyanine green, the value of the ratio $V_{\max }$ to $K_{m}$ (Keiding et al., 1976) is rather low, so that hepatic uptake is rather independent of blood flow and dependent on intrinsic hepatic clearance (Krarup and Larsen, 1976). However, for cholylglycine, the ratio of $V_{\max }$ to $\mathrm{K}_{\mathrm{m}}$ is high (Reichen and Paumgartner, 1976), so that blood flow is probably usually rate limiting. Thus, a possible value of cholylglycine clearance measurements will be as a convenient noninvasive method of estimating hepatic blood flow.

The present procedure is quite different in principle from the conventional BSP test which measures the amount of dye remaining in the circulation at 30 or 45 minutes. Such a test is only partially dependent on uptake of BSP by the liver, as the glutathione conjugate of BSP refluxes into blood and in turn is cleared slowly (Milanese et al., 1976).

The authors are indebted to Don Belobaba and Annie Ruben for assistance in the analyses and to Dr E. R. Dickson, Dr W. Baldus, Dr J. R. McPherson, and the late Dr W. H. J. Summerskill for referring patients with benign recurrent cholestasis.

\section{References}

Barnes, S., Thjodleifsson, B., Billing, B. H., and Sherlock, S. (1976). Plasma elimination of a tracer dose of cholyl $\left(1-{ }^{14} \mathrm{C}\right)$ glycine in liver disease. Clinical Science and Molecular Medicine, 51, 15p. (Abstract).

van Berge-Henegouwen, G. P., Brandt, K-H., and de Pagter, A.G.F. (1974). Is an acute disturbance in hepatic transport of bile acids the primary cause of cholestasis in benign recurrent cholestasis? Lancet, 1, 1249-1251.

Borgström, B., Dahlqvist, A., Lundh, G., and Sjövall, J. (1957). Studies of intestinal digestion and absorption in the human. Journal of Clinical Investigation, 36, 1521-1536.

Calcraft, B., LaRusso, N. F., Hofmann, A. F., and Belobaba, D. T. A. (1975). Development of a simple, safe, bile acid clearance test: The radio-cholate clearance test. Gastroenterology, 69, 812. (Abstract).

Fausa, O., and Gjone, E. (1976). Serum bile acid concentrations in patients with liver disease. Scandinavian Journal of Gastroenterology, 11, 537-543.

Ferguson, D. R., Calcraft, B. J., Hofmann, A. F., and Belobaba, D. T. A. (1976). Lack of sensitivity of a bile acid clearance test in the detection of liver disease. Gastro- enterology, 71, 905. (Abstract).

Goresky, C. A. (1964). Initial distribution and rate of uptake of sulfobromophthalein in the liver. American Journal of Physiology, 207, 13-26.

Keiding, S., Johansen, S., Winkler, K., Tønnesen, K., and Tygstrup, N. (1976). Michaelis-Menten kinetics of galactose elimination by the isolated perfused pig liver. American Journal of Physiology, 230, 1302-1313.

Krarup, N., and Larsen, J. A. (1976). The influence of dye infusion rate and hepatic plasma flow on indocyanine green clearance. Scandinavian Journal of Clinical and Laboratory Investigation, 36, 183-188.

LaRusso, N. F., Hoffman, N. E., Hofmann, A. F., and Korman, M. G. (1975). Validity and sensitivity of an intravenous bile acid tolerance test in patients with liver disease. New England Journal of Medicine, 292, 1209-1214.

Martin, J. F., Vierling, J. M., Wolkoff, A. W., Scharschmidt, B. F., Vergalla, J., Waggoner, J. G., and Berk, P. D. (1976). Abnormal hepatic transport of indocyanine green in Gilbert's syndrome. Gastroenterology, 70, 385-391.

Milanese, M., Molino, G., and Villa, A. (1976). Pathophysiological information on hepatic function from standard measurements of the kinetics of BSP. 4th Symposium on Identification and Parameter Estimation, Tbilisi (U.R.S.S.) (Abstract).

$\mathrm{Ng}, \mathrm{P}$. Y., and Hofmann, A. F. (1977). Tissue distribution of $\left[1^{14} \mathrm{C}\right]$ cholylglycine in rats and hamsters with a bile fistula or bile duct ligation. Proceedings of the Society for Experimental Biology and Medicine, 154, 134-137.

Okuda, K., Ohkubo, H., Musha, H., Kotoda, K., Abe, H., and Tanikawa, K. (1976). Marked delay in indocyanine green plasma clearance with a near-normal bromosulphophthalein retention: a constitutional abnormality? Gut, 17, 588-594.

Osuga, T., Mitamura, K., Mashige, F., and Imai, K. (1977). Evaluation of fluorimetrically estimated serum bile acid in liver disease. Clinica Chimica Acta, 75, 81-90.

de Pagter, A. G. F., van Berge-Henegouwen, G. P., Ten Bokkel Huinink, J. A., and Brandt, K-H. (1976). Familial benign recurrent intrahepatic cholestasis: Interrelation with intrahepatic cholestasis of pregnancy and from oral contraceptives? Gastroenterology, 71, 202-207.

Paumgartner, G. (1975). The handling of indocyanine green by the liver. Schweizerische Medizinische Wochenschrift, 105, Supplement 5.

Reichen, J., and Paumgartner, G. (1976). Uptake of bile acids by perfused rat liver. American Journal of Physiology, 231, 734-742.

Scharschmidt, B. F., Waggoner, J. G., and Berk, P. D. (1975). Hepatic organic anion uptake in the rat. Journal of Clinical Investigation, 56, 1280-1292.

Simmonds, W. J., Korman, M. G., Go, V. L. W., and Hofmann, A. F. (1973). Radioimmunoassay of conjugated cholyl bile acids in serum. Gastroenterology, 65, 705-711.

Summerskill, W. H. J. (1965). The syndrome of benign recurrent cholestasis. American Journal of Medicine, 38, 298-305.

Summerskill, W. H. J., and Walshe, J. M. (1959). Benign recurrent intrahepatic 'obstructive' jaundice. Lancet, 2, 686-690.

Tygstrup, N., and Jensen, B. (1969). Intermittent intrahepatic cholestasis of unknown etiology in five young males from the Faroe Islands. Acta Medica Scandinavica, 185, 523530. 